\title{
Reflexões e considerações acerca do ensino-aprendizagem do gênero Curriculum vitae na formação docente inicial de língua inglesa
}

\section{Reflections and considerations about the teaching and learning of the genre Curriculum vitae in pre-service English teacher education}

Carmen Ilma Belincanta Borghi*

Universidade Estadual de Maringá

Luciana Cabrini Simões Calvo**

Universidade Estadual de Maringá

Maria Adelaide de Freitas***

Universidade Estadual de Maringá

RESUMO: Situando-se dentro da perspectiva sociointeracionista, este trabalho visa discutir dados recortados de uma pesquisa desenvolvida com o gênero curriculum vitae $(\mathrm{CV})$, em inglês, por meio de uma sequência didática elaborada especificamente para tal fim e aplicada a acadêmicas do $4^{\circ}$ ano do curso de Letras Português/Inglês, da Universidade Estadual de Maringá, em 2009. Como aporte teórico, utilizamos a concepção bakhtiniana de gêneros discursivos, a proposta de sequência didática e a discussão sobre lista de controle para correção da produção escrita dos alunos. Os resultados apontam algumas lacunas observadas no desenvolvimento do trabalho e mostram que, dentre as capacidades de linguagem trabalhadas, as capacidades discursiva e linguístico-discursiva são mais desenvolvidas do que a capacidade de ação na produção final das acadêmicas.

PALAVRAS-CHAVE: Formação docente inicial; gêneros discursivos; sequência didática; Curriculum vitae.

ABSTRACT: Grounded on the socio-interactionist perspective, this work aims at discussing data of a research carried out by means of a didactic sequence of the genre Curriculum vitae (CV), in English. This didactic sequence was developed

*caborghi@onda.com.br

** cabrinisimoes@gmail.com

***mafreitas7@gmail.com 
with 4th year students of the Language Arts Undergraduate Course - Portuguese/ English, at the State University of Maringá. Theoretical assumptions are drawn from the bakhtinian notion of discursive genres, from the concept of didactic sequence and from the discussion about control lists. The data demonstrate some gaps observed during the development of the sequence. They also show that, among the language capacities taught in the sequence, the discursive and linguisticdiscursive ones are more developed than the action capacity in the students' final production.

KEYWORDS: Pre-service teacher education; discursive genres; didactic sequence; curriculum vitae.

\section{Introdução}

O ensino-aprendizagem de línguas tem sido alvo de especial interesse de estudos linguístico-discursivos nos últimos tempos. Questiona-se, em tais estudos, o tratamento inadequado conferido ao texto geralmente concebido como pretexto para um ensino limitado ao vocabulário e às estruturas gramaticais. Tal tratamento decorre de uma visão de língua / linguagem como sistema, entendendo o significado como imanente ao texto, ficando, portanto, nele aprisionado. Contrapõe-se a tal noção a de discurso que, além dos aspectos linguísticos de um texto, considera os aspectos sócio-históricos a partir dos quais o significado é construído.

Assim, mais recentemente, discussōes e reflexōes acerca do uso de gêneros discursivos no ensino-aprendizagem de línguas têm permeado as esferas educacionais, mais especificamente, as áreas de Letras e Linguística com enfoque especial na Formação de Professores de línguas estrangeiras. Tais discussões e reflexões parecem afetar diretamente a elaboração de políticas públicas educacionais no que concerne ao ensino de tais línguas. Deparamonos com a manifestação dessas políticas em forma de documentos oficiais como os Parâmetros Curriculares Nacionais- Língua Estrangeira (PCN-LE) (BRASIL, 1998), as Orientações Curriculares para o Ensino Médio - Língua Estrangeira (OCEM) (BRASIL, 2006) e as Diretrizes Curriculares do Estado do Paraná para línguas estrangeiras (DCE-PR) (PARANÁ, 2008), documentos esses que preconizam propostas de ensino-aprendizagem de línguas norteadas pela questão discursiva.

Dentre os autores que apresentam teorias embasadoras para o trabalho com gêneros, encontram-se Bakhtin (2003); Bonini (2001); Meurer (2000); Dolz, Noverraz e Schneuwly (2004); Pasquier e Dolz (1996). Já dentre os pesquisadores que contribuem com propostas de e sobre o trabalho com 
gêneros no processo de ensino-aprendizagem de línguas estrangeiras, citam-se Tamarozi e Cristovão (2007), Cristovão (2007), Calvo e Borghi (2009).

Embora algumas pesquisas na área de ensino-aprendizagem de línguas abarquem questóes inerentes ao uso de gêneros como instrumento ou objeto de ensino (CRISTOVÃO, 2007; DIONISIO; MACHADO; BEZERRA, 2005; KARWOSKI, GAYDECZKA; BRITO, 2006), tal área ainda carece de estudos que apontem as possíveis lacunas ou mudanças que o aporte teórico ou o desenvolvimento do próprio trabalho sugere.

Dessa forma, neste artigo descrevemos e discutimos dados recortados de um trabalho desenvolvido, em contexto de formação docente inicial, com o gênero Curriculum vitae (CV), em inglês, por meio de uma sequência didática elaborada especificamente para tal fim. $\mathrm{O}$ objetivo inicial da pesquisa sobre o trabalho, considerando que ele foi concebido como tendo um caráter investigativo além de pedagógico, era compreender como o desenvolvimento de um trabalho dessa natureza pode afetar o processo de ensino- aprendizagem de inglês. Tornando tal objetivo mais específico durante o desenvolvimento da pesquisa, buscou-se também examinar como ocorre o desenvolvimento das acadêmicas participantes no que concernem as diferentes capacidades de linguagem trabalhadas e o que os dados podem sugerir dos procedimentos pedagógicos e analíticos usados pelas professoras-pesquisadoras.

A presente investigação faz parte de um projeto de pesquisa realizado na Universidade Estadual de Maringá, intitulado "Gêneros Discursivos por meio de sequências didáticas na formação docente inicial”. O projeto está inserido no Grupo de Pesquisa "Interação e Escrita" (CNPq/UEM-www.escrita.uem.br).

As razóes que motivaram o desenvolvimento do mencionado trabalho e sua respectiva investigação podem ser resumidas nos seguintes aspectos: a) a relevância e a necessidade de se pensar em objetivos outros para o estudo do texto, para que ele não seja tratado apenas como pretexto para o ensino de estruturas gramaticais; b) a ausência de um trabalho com gêneros discursivos nos diversos contextos de ensino de língua inglesa como regra geral; c) o reconhecimento de que o ensino com base nos gêneros discursivos não faz parte do arquitexto da maioria dos profissionais de ensino de línguas.

Tendo em vista os objetivos propostos, este texto está dividido em quatro partes, além da presente introdução. Temos, então, os pressupostos teóricos que abarcam três subseçôes: o ensino-aprendizagem de gêneros discursivos; sequência didática: um procedimento de trabalho com gêneros discursivos; modelo didático e lista de controle: instrumentos para o uso de 
sequências didáticas. Aos pressupostos teóricos seguem as seçōes: da descrição metodológica da pesquisa, da apresentação e discussão dos dados e das considerações finais.

\section{A discussão teórica}

A presente seção está organizada nas três subseções nomeadas no último parágrafo acima, seguindo também a mesma sequência indicada.

\section{O ensino-aprendizagem de gêneros discursivos}

Para Bakhtin (2003), aprender a falar está intimamente ligado ao processo da construção de enunciados, entendendo-se por enunciados os diferentes tipos de textos, tanto orais quanto escritos, ou seja, unidades reais de comunicação. O enunciado, conforme explicam Brait e Melo (2005), é tido como produto do processo de enunciação que nele deixa marcas de subjetividade, de intersubjetividade, de alteridade que caracterizam a linguagem em uso, considerando-se a interação em que ocorre e o contexto mais amplo que o abriga. Dependendo de onde circulamos, elaboramos o nosso enunciado para que a comunicação se estabeleça. Os diferentes tipos de enunciados são determinados pelas condições específicas e pelos objetivos de cada esfera de comunicação. Dessa forma, cada contexto de utilização da língua "elabora tipos relativamente estáveis de enunciados" (BAKHTIN, 2003, p. 262), denominados gêneros do discurso. A expressão "relativamente estável" refere-se ao caráter sócio-histórico do gênero, pois, à medida que as esferas de comunicação evoluem, novos gêneros são criados, recriados ou desaparecem.

Sendo assim, salientamos que, quanto mais gêneros dominarmos, mais capazes seremos de "realizar de modo mais acabado o nosso livre projeto de discurso" (BAKHTIN, 2003, p. 285). Isso quer dizer que, mesmo dominando, de um modo geral, a língua materna ou estrangeira, por exemplo, uma pessoa que não domine certos gêneros, não conseguirá participar plenamente das esferas de comunicação em que eles circulam:

[m]uitas pessoas que dominam magnificamente uma língua sentem amiúde total impotência em alguns campos da comunicação precisamente porque não dominam na prática as formas de gênero de dadas esferas. Freqüentemente, a pessoa que domina magnificamente o discurso em diferentes esferas da comunicação cultural sabe ler o relatório, desenvolve uma discussão científica, fala magnificamente 
sobre questôes sociais, cala ou intervém de forma muito desajeitada em uma conversa mundana. Aqui não se trata de pobreza vocabular nem de estilo tomado de maneira abstrata; tudo se resume a uma inabilidade para dominar o repertório dos gêneros da conversa mundana, a uma falta de acervo suficiente de noções sobre todo um enunciado que ajudem a moldar de forma rápida e descontraída o seu discurso nas formas estilístico-composicionais definidas, a uma inabilidade de tomar a palavra a tempo, de começar corretamente e terminar corretamente (nesses gêneros, a composição é muito simples). (BAKHTIN, 2003, p. 284, 285).

No que diz respeito às propostas de ensino-aprendizagem de língua estrangeira, podemos afirmar que a noção bakhtiniana de gêneros discursivos permeia os entendimentos subjacentes a propostas dos documentos oficiais para tal ensino. Como exemplo, citamos as Diretrizes Curriculares da Rede Pública de Educação Básica do Estado do Paraná-LE (PARANÁ, 2008). Refletindo os estudos contemporâneos sobre a questão linguística, neste documento, "a língua é concebida como discurso, não como estrutura ou código a ser decifrado, constrói significados e não apenas os transmite" (PARANÁ, 2008, p. 53).

Consoantes a essa noção de língua e de seu ensino, muitos pesquisadores apontam para a importância do trabalho, e respectiva pesquisa, com gêneros discursivos na escola. Bonini (2001), por exemplo, entende que a maneira como o ensino de línguas vem sendo trabalhado nas escolas, ou seja, com ênfase nos aspectos formais, desestrutura a competência comunicativa do aluno, retirando da linguagem a sociedade e a interação. Dessa forma, o autor expóe que "é principalmente com base neste tipo de crítica que muitos estudiosos encaminham suas reflexões para o conceito de gênero que, mesmo ainda em formação, apresenta grande potencialidade de resolver a questão" (BONINI, 2001, p. 8).

Meurer (2000, p. 153), por sua vez, assevera que

a pesquisa e o ensino baseados em estudos de gêneros textuais poderão estimular o estudo da língua (materna e estrangeira) a se transformar em um contexto destinado ao levantamento das muitas maneiras de manifestações orais e escritas. Tal tipo de prática poderá auxiliar os indivíduos a perceberem quem são e onde se encontram, como os textos funcionam ao conduzir a cultura atual e ao reconstituir culturas de outras épocas. 
Já Tamarozi e Cristovão (2007) afirmam que o trabalho com gêneros pode ser de grande ajuda aos alunos quando utilizados numa interação prática, para se analisar sua utilidade social. As autoras também salientam que, na prática com gêneros textuais, o aluno se encontra mais perto da realidade em que vive. "É para a sociedade em que ele vive que ele precisa saber como usar os gêneros, tanto para se comunicar com seus conhecidos quanto com os desconhecidos, por exemplo, numa situação profissional" (TAMAROZI; CRISTOVÃO, 2007, p. 31).

Assim, evidenciamos que o ensino de línguas não se limita à reprodução de regras gramaticais e traduções. Para que os alunos ajam de maneira crítica na sociedade e dela possam usufruir de maneira mais justa e democrática, é de suma relevância que tenham contato com os mais diversos gêneros que circulam em nosso meio, pois, dessa maneira, eles compreenderão as diversas formas de materialização da linguagem, entendendo o contexto de produção do texto, as capacidades de linguagens necessárias para apropriação e uso/ entendimento de um determinado gênero. Qualificam-se, portanto, como cidadãos mais bem preparados para viverem e agirem na sociedade, participando de sua transformação sempre que necessário.

\section{Sequência didática: um procedimento de trabalho com gêneros discursivos}

No que tange à operacionalização do ensino de línguas por meio dos gêneros, Dolz, Noverraz e Schneuwly (2004, p. 97) propõem um procedimento específico que denominam sequência didática, concebida como "um conjunto de atividades escolares organizadas, de maneira sistemática, em torno de um gênero textual oral ou escrito". Seu objetivo é ajudar o aluno a melhor se apropriar de um gênero. Nesse sentido, faz-se necessária a escolha de gêneros que os alunos não dominem totalmente, pois entendem os autores que as sequências didáticas têm a função de dar acesso aos alunos a práticas de linguagem novas ou dificilmente domináveis.

Os autores oferecem uma representação esquemática da sequência didática que reproduzimos a seguir: 


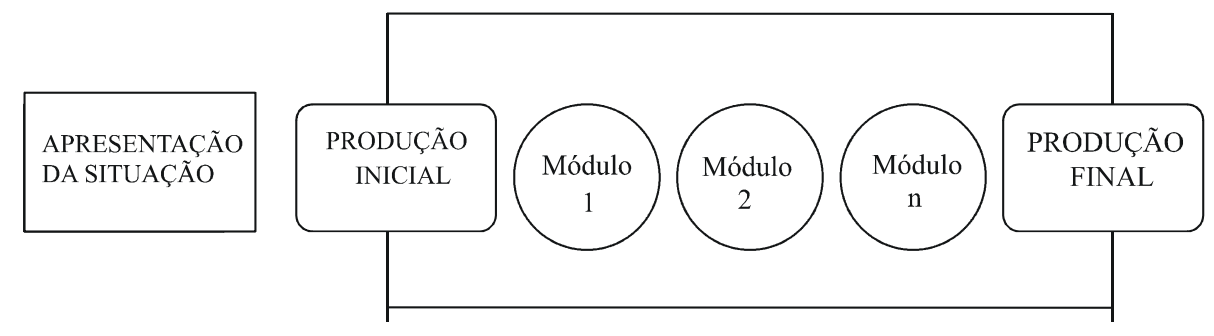

FIGURA 1 - Esquema da sequência didática (DOLZ; NOVERRAZ; SCHNEUWLY, 2004, p. 98)

Como primeira parte da sequência, a apresentação da situação é o momento em que os alunos fazem uma representação da situação de comunicação e do gênero a ser trabalhado, ou seja, há uma contextualização sobre o gênero que será trabalhado, explicitando para os alunos a situação de produção, isto é, qual gênero será abordado, com qual objetivo, quem serão os destinatários daquele texto e onde ele circulará. Os alunos, portanto, conseguirão fazer uma imagem possível de uma situação concreta para a produção de seu texto.

$\mathrm{Na}$ segunda parte, a da produção inicial ou primeira produção, os alunos elaboram um texto escrito ou oral do gênero a ser trabalhado com o conhecimento, ou com a falta dele, que detêm naquele momento. A primeira produção serve como um diagnóstico tanto para os alunos como para o professor. Os alunos conseguem descobrir, no momento da realização dessa produção e, posteriormente, quando recebem sua produção de volta com apontamentos do professor, o que já sabem fazer e se conscientizam dos problemas que eles mesmos, ou outros alunos, apresentam. $O$ professor, por sua vez, usa tal diagnóstico para adaptar as atividades que integrarão os vários módulos da sequência didática, de acordo com as dificuldades apontadas dos alunos.

Os módulos, portanto, são atividades para se trabalharem os problemas que aparecerem na primeira produção, visando a oferecer aos alunos os instrumentos necessários para superá-los. No desenvolvimento dos módulos, é de extrema importância que se variem as atividades e os exercícios propostos, pois, segundo Dolz, Noverraz e Schneuwly (2004, p. 105), será dada a cada aluno "a possibilidade de ter acesso, por diferentes vias, às noçóes e aos instrumentos, aumentando, desse modo, suas chances de sucesso". Além disso, entende-se que tal variedade possibilita a mobilização de diferentes capacidades cognitivas dos alunos. 
Ao elaborar sua produção final, o aluno coloca em prática o conhecimento apropriado durante a realização das atividades nos diferentes módulos, podendo fazer, a nosso ver, uso das várias ferramentas mediadoras para tal: o material usado nas atividades, materiais próprios, como o dicionário, sua produção inicial com os apontamentos das professoras, dentre outras possibilidades.

\section{Modelo didático e lista de controle: instrumentos para o uso de sequências didáticas}

Antes da elaboração de uma sequência didática, entretanto, é imprescindível que seja construído um modelo didático do gênero a ser trabalhado. Para tal criação, devem-se respeitar, segundo Schneuwly e Dolz (2004, p. 81), alguns princípios. O de legitimidade em que se faz "referência aos saberes teóricos ou elaborados por especialistas". O de pertinência em que se faz "referência às capacidades dos alunos, às finalidades e aos objetivos da escola, aos processos de ensino-aprendizagem". E, por fim, o de solidarização quando se procura "tornar coerentes os saberes em função dos objetivos visados".

Cristovão (2007) reenfatiza tais princípios, apontando para a necessidade da criação de um modelo didático a partir dos seguintes elementos:

a) dos resultados de aprendizagem expressos por documentos oficiais e da determinação das capacidades reveladas pelos alunos;

b) dos conhecimentos dos especialistas daquele gênero e dos conhecimentos linguísticos já elaborados por eles;

c) das capacidades de linguagem ${ }^{1}$ dos alunos.

No que concernem as características de um modelo didático, Schneuwly e Dolz (2004) salientam duas. A primeira entende que o modelo constitui

${ }^{1}$ Citados por Cristovão (2005), Dolz, Pasquier e Bronckart (1993) e Dolz e Schneuwly (1998) indicam três tipos de capacidades de linguagem: as capacidades de ação, que têm como objetivo "o reconhecimento do gênero e de sua relação com o contexto de produção e mobilização de conteúdos"; as capacidades discursivas, as quais trabalham com o "reconhecimento do plano textual de cada gênero, os tipos de discurso e de sequências mobilizados"; e as capacidades linguísticodiscursivas, as quais visam o "reconhecimento e a utilização do valor das unidades linguístico-discursivas inerentes a cada gênero para a construção do significado global do texto" (CRISTOVÃO, 2005, p. 175). 
uma síntese com objetivo prático, destinada a orientar as intervenções dos professores. A segunda diz que ele evidencia as dimensões ensináveis, com base nas quais diversas sequências didáticas podem ser concebidas.

Sendo assim, o modelo didático, de certa forma, pode estabelecer os parâmetros para os professores avaliarem a primeira produção escrita, caso ainda não tenha sido elaborada uma lista de controle. Nesse caso, a lista de controle é elaborada após a primeira produção, o que ocorreu neste estudo.

A função da lista de controle consiste, segundo Pasquier e Dolz (1996 apud CRISTOVÃO; TORRES, 2006, p. 45-46), em um instrumento para levantar os problemas de produção escrita que os alunos apresentam quando iniciam a aprendizagem de determinado gênero e também para gerenciar sua reescrita e, posteriormente transformar-se em um regulador interno dele.

A lista de controle oferece ao aluno uma possibilidade de regulação externa, pois é utilizada na primeira etapa da avaliação para diagnosticar os problemas de produção escrita que os alunos tinham antes do ensino. A lista pode, progressivamente, converter-se em um instrumento de regulação interna na medida em que o aluno passa a controlar as habilidades necessárias à produção de um gênero textual e não precisa mais do apoio exterior da lista de controle.

Tendo em vista sua função e a última citação, de acordo com Cristovão e Torres (2006), a lista de controle pode contribuir, portanto, para o fortalecimento da autonomia do aluno, uma vez que ele pode adquirir gradualmente um maior domínio das diferentes dimensões que envolvem a produção escrita. As autoras ainda esperam que "ao confrontar o seu próprio texto, ou o texto do colega com a lista de controle, o aprendiz não apenas identifique o que precisa ser modificado, mas tenha também um parâmetro a partir do qual possa implementar a modificação" (p. 202).

$\mathrm{Na}$ mesma linha das autoras, Bain e Schneuwly (1993), citados por Gonçalves (2007, p. 118), também apontam a ajuda que a lista de controle proporciona aos alunos no processo de aprendizagem da escrita.

A lista de controle serve de baliza à aprendizagem. Ela ajuda os estudantes a antecipar ou a compreender os critérios de avaliação de seus textos, a fazer uma autocrítica de suas produçôes e, a partir deste momento, a estruturar e a modelar sua escrita no curso de sua realização. Finalmente, ela permite ao estudante avaliar seu progresso (principalmente durante a comparação entre o pré-texto e o pós-texto). 
No que tange a sua elaboração, Schneuwly (1993 apud GONÇALVES, 2007) assevera que a lista de controle pode ser feita pelos estudantes, pela turma como um todo ou pode ser elaborada pelo professor. No caso específico deste estudo, a lista de controle foi elaborada pelas professoras-pesquisadoras com base nas características e conceitos do gênero $\mathrm{CV}$ que compõem o respectivo modelo didático.

Embora haja sugestôes de se elaborar a lista de controle juntamente com os alunos, logo após a primeira versão do texto-gênero, acreditamos que, neste momento, pode ser ainda cedo para que os alunos participem da construção da lista, pois eles se encontram no início do processo de apropriação das características do gênero em si.

Finalizando a resenha das questôes destacadas dentro do escopo teórico que subsidia os estudos sobre os gêneros discursivos tomados como instrumentos ou objetos de ensino na área do ensino-aprendizagem de línguas, a intenção é que ela permita ao leitor um melhor acompanhamento da descrição, e posterior apresentação e discussão dos dados recortados para o presente artigo.

\section{Descrição metodológica da pesquisa}

Retomando o objetivo inicial deste estudo de natureza interventivointrepretativa, qual seja, o de compreender como o trabalho desenvolvido com o gênero Curriculum vitae (CV) em inglês, por meio de uma sequência didática (DOLZ; NOVERRAZ; SCHNEUWLY, 2004) elaborada especificamente para tal fim pode afetar o processo de ensino-aprendizagem do idioma em questão, descrevemos, nesta seção, alguns procedimentos metodológicos que orientaram a análise dos dados.

Convém salientar que compóe o recorte de dados, que aqui trazemos, a produção inicial em inglês do $\mathrm{CV}$, realizada por sete acadêmicas do $4^{\circ}$ ano de um curso de Letras, participantes da pesquisa, produção essa, como intencionado, possuía função diagnóstica. Compõe também os dados uma segunda produção de $\mathrm{CV}$ das acadêmicas, após a intervenção feita via sequência didática, visando o estudo do referido gênero. Tais produçôes ocorreram no período em que a respectiva sequência didática foi desenvolvida, ou seja, entre 26 de junho e 6 de julho de 2009. Tais dados têm um caráter central neste estudo, porém, usamos, em medida contida, dados resultantes de um questionário respondido pelas acadêmicas para evidenciar algumas de nossas interpretações dos resultados apontados pelos dados centrais. 
Duas das autoras desse artigo desempenharam o papel de formadoraspesquisadoras, responsáveis que foram, além da atividade investigativa, pela proposta do trabalho, pelo seu planejamento e pelo desenvolvimento das atividades. A terceira desempenhou o papel de pesquisadora auxiliar, tendo por função a observação das aulas, a orientação de instrumentos complementares de coleta de dados e a participação nas respectivas análises, interpretações e divulgação dos resultados.

As acadêmicas investigadas compõem uma das turmas de $4^{\circ}$ ano da instituição pesquisada, cursando a disciplina de Oficina de Leitura e Produção Escrita em Língua Inglesa III, e o espaço para a realização do trabalhoinvestigação foi cedido pela formadora responsável por tal disciplina. Devido a alteraçōes na distribuição de disciplinas do ano em questão, esse fato caracterizou uma mudança no planejamento inicial, o qual previa que o referido trabalho fosse desenvolvido com os próprios alunos de uma das formadoras-pesquisadoras, ministrante da disciplina até então. As acadêmicas, porém, tinham contato com essa formadora na disciplina de Prática de Formação do Professor de Língua Inglesa por ela ministrada.

No que tange ao tratamento recebido pelos dados sob análise, ele se configurou no levantamento, pelas pesquisadoras, dos diferentes aspectos do gênero $\mathrm{CV}$, observados tanto na produção inicial quanto na segunda produção das acadêmicas. $\mathrm{O}$ modelo didático do gênero $\mathrm{CV},{ }^{2}$ elaborado pelas formadoras-pesquisadoras, serviu de base para o primeiro levantamento e, além dele, uma lista de controle, ${ }^{3}$ também elaborada por elas, embasou o segundo levantamento. Vale ressaltar que, enquanto o modelo didático esteve ao alcance apenas das formadoras-pesquisadoras para o levantamento dos aspectos do gênero na primeira produção, a lista de controle foi entregue às acadêmicas para que a usassem como uma das ferramentas mediadoras por ocasião de sua segunda produção, com sua produção inicial e o respectivo levantamento feito pelas formadoras a partir do modelo didático. É relevante ainda destacar que outros aspectos que se configuraram como extramodelo didático e extralista de controle, por não terem sido previstos nesses instrumentos, também foram incluídos nos levantamentos. Entendemos que tal inclusão se deve a um momento de maior distanciamento das formadoraspesquisadoras a partir do produto, no caso as duas produçóes, ao passo que a

${ }^{2}$ Veja o resumo do modelo didático do CV no APÊNDICE A.

${ }^{3}$ Apresentada no APÊNDICE B. 
elaboração do modelo didático e da lista de controle decorre de uma situação de maior envolvimento delas com o processo de elaboração e desenvolvimento das atividades previstas. O surgimento desses extras nos levantamentos, então, pode desempenhar o papel de apontar outras possibilidades de intervenção nos procedimentos de elaboração, desenvolvimento e orientação de futuros trabalhos com outros gêneros discursivos por meio de sequências didáticas.

Com os levantamentos em mãos, além das produçôes escritas originais, permitindo um olhar analítico dos referidos dados, os quais se configuravam, então, como de natureza mais ampla e 'misturada', sentimos a necessidade de organizá-los de um modo que permitisse um olhar mais nítido dos resultados da apropriação do gênero trabalhado. Ocorreu-nos, então, organizá-los em um quadro que agrupasse tanto os resultados da primeira quanto da segunda produção materializados nos levantamentos. Além disso, julgamos especialmente importante, para uma melhor compreensão e visualização, que tais resultados fossem também organizados de acordo com as capacidades de linguagem (de ação, discursiva e linguístico-discursiva), ${ }^{4}$ uma vez que elas foram alvo de atenção na elaboração e no desenvolvimento das atividades com as acadêmicas. Dessa forma, seria mantida a consistência entre o processo pedagógico do ensino do gênero em questão e o processo analítico dos dados. Os quadros apresentados na próxima seção ilustram a organização dos resultados das produçōes conforme os procedimentos acima descritos.

Com o levantamento dos dados concernentes às produções das acadêmicas organizados nos referidos quadros, tornou-se possível especificar dois outros objetivos, conforme assinalado na introdução deste artigo, os quais se materializam nas seguintes perguntas: como se pode observar o desenvolvimento das acadêmicas no que tange às diferentes capacidades de linguagem, tomando por base sua produção inicial e sua segunda produção de um CV em inglês?; o que os dados (quadros) podem sugerir dos procedimentos pedagógicos e analíticos das formadoras-pesquisadoras?

Ressaltamos que tais perguntas indicam que, a partir da comparação entre as produçôes inicial e final, são feitas inferências sobre os procedimentos pedagógicos e analíticos empregados, no sentido de apontar para as possíveis explicações para os resultados alcançados. Antecipamos que tais explicações remetem a ferramentas mediadoras, as quais não são, entretanto, sistematicamente investigadas nesse momento.

${ }^{4}$ Veja rodapé número 1 para uma rápida explicação de tais capacidades. 
A seção seguinte se ocupará das questōes levantadas e a subsequente fará menção ao objetivo primeiro mencionado no início desta seção.

\section{Apropriação do gênero CV: produções-produto e as capacidades de linguagem}

Antes de iniciarmos a apresentação dos resultados e sua discussão, propriamente ditas, vale reenfatizar a importância de se desenvolver o ensinoaprendizagem de línguas, tomando por base um trabalho com gêneros discursivos vistos como objeto de conhecimento.

Assim, retomamos Tamarozi e Cristovão (2007) para salientar a necessidade que elas apontam de que o trabalho com gêneros se configure como uma interação prática para que os alunos que dela participem possam analisar sua utilidade social. As autoras argumentam que esse trabalho passa a ser significativo na medida em que prepara o aluno para usar os gêneros aprendidos na realidade em que vive, capacitando-os a desenvolverem uma comunicação, tanto com conhecidos quanto desconhecidos em situaçóes de sua esfera profissional, além de outras, poderíamos acrescentar. Para tanto, entende-se que o trabalho com os gêneros no contexto de ensino-aprendizagem de línguas estrangeiras pode contribuir com a construção de alunos críticos. Assim, ao se apropriarem e compreenderem as diversas possibilidades de materialização da linguagem, entendendo o contexto de produção do texto, as capacidades de linguagens necessárias para apropriação e uso / entendimento de um determinado gênero, tais alunos provavelmente estarão mais aptos a intervir de modo mais amplo e intenso na sociedade em que vivem.

Os dados para análise foram agrupados, conforme apontado anteriormente, em quadros, a partir do levantamento das características do gênero na produção escrita dos alunos, tendo como base as capacidades de linguagem no que concerne ao gênero Curriculum vitae.

Da análise dos dados, obtivemos alguns resultados referentes aos aspectos evidenciados de acordo com as características do modelo didático de gênero, utilizado na avaliação da primeira produção escrita, e da lista de controle, usada na segunda produção, como já descrito na seção metodológica.

Primeiramente, em relação aos dados recortados, observamos que, em sua maioria, os aspectos levantados na correção da primeira versão da produção escrita do gênero $\mathrm{CV}$ foram predominantemente negativos, diferentemente dos aspectos levantados na segunda produção, os quais foram, também em sua 
maior parte, positivos. ${ }^{5}$ A título de ilustração, vejamos o exemplo do levantamento das duas produçôes de uma das acadêmicas participantes (Gi).

QUADRO 1

Levantamento dos aspectos característicos do gênero CV das produçōes de Gi

\begin{tabular}{|c|c|c|}
\hline Produçôes & $\begin{array}{l}\text { Capacidades } \\
\text { de linguagem }\end{array}$ & Modelo didático resumido \\
\hline \multirow{3}{*}{$\begin{array}{c}1^{\mathrm{a}} \\
\text { produção }\end{array}$} & $\begin{array}{l}\text { Capacidade } \\
\text { de ação }\end{array}$ & \\
\hline & $\begin{array}{l}\text { Capacidade } \\
\text { discursiva }\end{array}$ & $\begin{array}{l}\text { (-) no use of space between the headings; } \\
\text { (-) no use of dates; } \\
\text { (-) not organized information } \\
\text { under the headings "Study and courses" and } \\
\text { "Professional Experience"; } \\
\text { (+) use of "markers" to indicate different activities. }\end{array}$ \\
\hline & $\begin{array}{c}\text { Capacidade } \\
\text { linguístico-discursiva }\end{array}$ & (-) no use of specific words / terms; \\
\hline & & Lista de controle \\
\hline \multirow{3}{*}{$\begin{array}{c}2^{\mathrm{a}} \\
\text { produção }\end{array}$} & $\begin{array}{l}\text { Capacidade } \\
\text { de ação }\end{array}$ & \\
\hline & $\begin{array}{l}\text { Capacidade } \\
\text { discursiva }\end{array}$ & $\begin{array}{l}\text { (+) use of space between the headings; } \\
\text { (+) use of dates; } \\
\text { (+) use of reverse chronological order; } \\
\text { (+) use of markers maintained; } \\
\text { (+) organized information under the heading } \\
\text { "Study and Courses"; } \\
\text { (+) organized information under the heading } \\
\text { "Professional Experience"; } \\
\text { (+) she created a heading (Participation in Events) } \\
\text { to include information about her participation } \\
\text { in events; } \\
\text { (+) according to the other CVS she read in class, } \\
\text { she uses the heading "Other information" to } \\
\text { mark her linguistic abilities. }\end{array}$ \\
\hline & $\begin{array}{c}\text { Capacidade } \\
\text { linguístico-discursiva }\end{array}$ & $\begin{array}{l}\text { (+) use of specific words; } \\
\text { (+) use of action verbs (included). }\end{array}$ \\
\hline
\end{tabular}

${ }^{5}$ Informamos que os símbolos (-) e (+) usados nos quadros indicam respectivamente os aspectos negativos e os positivos. 
Essa grande alteração de aspectos negativos para positivos se deu pelos variados tipos de mediações que as alunas tiveram no decorrer do desenvolvimento da sequência didática (SD), embora tais tipos não tenham ainda sido investigados de forma mais sistemática e abrangente, como já pontuado. Algumas dessas mediações incluem: os exercícios da SD, os quais foram formulados com base nas diferentes capacidades de linguagem, as professoras, as colegas acadêmicas, a lista de controle, o uso espontâneo do dicionário, os apontamentos da produção inicial.

Vale recuperar a posição de Dolz, Noverraz e Schneuwly (2004), por exemplo, quando asseveram que o desenvolvimento dos diferentes módulos de uma sequência didática por meio de atividades também diferentes visa a oferecer os devidos instrumentos (as ditas ferramentas pedagógicas) para se superarem problemas encontrados. Desse modo, aumentam as chances de sucesso de cada aluno ao ter acesso, por diferentes vias, às noçóes e aos referidos instrumentos (destaques nossos).

Embora não fazendo parte do corpo central de dados sob análise no momento, depoimentos de acadêmicas, coletados por meio de outro instrumento de pesquisa nela utilizado, evidenciam a possível explicação do resultado ora discutido.

As aulas foram sobre um conteúdo importante $(\mathrm{CV})$ e as professoras souberam desenvolvê-lo muito bem, com estratégias de ensino que puderam desenvolver o básico de English que eu tenho (A5).

As aulas foram sendo desenvolvidas de acordo com o planejado, houve detalhamento das atividades, assim como do conteúdo. Apresentaram, primeiramente, o assunto, depois o gênero, alguns exercícios e por último a produção de um $\mathrm{CV}$ (A6).

Estreitamente ligada aos aspectos negativos e positivos marcados nos levantamentos das produções das acadêmicas referidos acima, agora no que diz respeito a uma atividade das formadoras-pesquisadoras, uma lacuna foi observada no levantamento do desenvolvimento da primeira produção, lacuna essa que se configura na quase ausência da marcação de aspectos positivos. A acentuada ênfase em sua marcação dos aspectos negativos sugere que as formadoras-pesquisadoras adotam uma atitude comum entre professores: a de salientarem usualmente os pontos negativos mais do que os positivos nas produções de seus alunos. Os exemplos de Me e Lo, nos QUADROS 2 e 3, respectivamente, procuram ilustrar a questão levantada. 
QUADRO 2

Levantamento dos aspectos característicos do gênero $\mathrm{CV}$ da primeira produção de $\mathrm{Me}$

\begin{tabular}{c|c|l}
\hline Produções & \multicolumn{1}{|c|}{$\begin{array}{c}\text { Capacidade } \\
\text { de linguagem }\end{array}$} & \multicolumn{1}{c}{ Modelo didático resumido } \\
\hline \multirow{4}{*}{$\begin{array}{c}1^{\mathbf{a}} \\
\text { produção }\end{array}$} & $\begin{array}{c}\text { Capacidade } \\
\text { de ação }\end{array}$ & \\
\cline { 2 - 3 } & Capacidade discursiva & $\begin{array}{l}(-) \text { no use of dates; } \\
(-) \text { no use of reverse chronological order of } \\
\text { the information; } \\
(+) \text { subtitles / headings are emphasized. }\end{array}$ \\
\cline { 2 - 3 } & $\begin{array}{c}\text { Capacidade } \\
\text { linguístico-discursiva }\end{array}$ & $\begin{array}{l}(-) \text { not appropriate / wrong terms; } \\
(-) \text { wrong use of specific words / terms. }\end{array}$ \\
\hline
\end{tabular}

QUADRO3

Levantamento dos aspectos característicos do gênero $\mathrm{CV}$ da primeira produção de Lo

\begin{tabular}{c|c|c}
\hline Produçóes & \multicolumn{1}{c|}{$\begin{array}{c}\text { Capacidades } \\
\text { de linguagem }\end{array}$} & \multicolumn{1}{c}{ Modelo didático resumido } \\
\hline \multirow{4}{*}{$\begin{array}{c}1^{\mathbf{a}} \\
\text { produção }\end{array}$} & $\begin{array}{c}\text { Capacidade } \\
\text { de açáo }\end{array}$ & \\
\cline { 2 - 3 } & Capacidade discursiva & $\begin{array}{l}(-) \text { no use of dates referring to professional life; } \\
(+) \text { use of chronological order of the information; } \\
(-) \text { not complete information about the activities; } \\
(-) \text { lack of detailed information (conferences). }\end{array}$ \\
\cline { 2 - 3 } & $\begin{array}{c}\text { Capacidade } \\
\text { linguístico-discursiva }\end{array}$ & $\begin{array}{l}(-) \text { no use of specific words / terms; } \\
(+) \text { use of action verbs in the past. } \\
(-) \text { no explanation about the abbreviations. }\end{array}$ \\
\hline
\end{tabular}

No caso específico da acadêmica Lo, notamos essa lacuna de um modo mais visível quando, em sua segunda produção (exemplificada no QUADRO 4 adiante, com destaque no exemplo que ilustra a questão ora discutida), evidenciamos, na capacidade discursiva, o seguinte aspecto levantado, com base na lista de controle: "subtitles / headings continue to be emphasized" (destaque nosso), sugerindo, portanto, que ela já havia contemplado tal questão em sua primeira produção. Entretanto, nota-se, pelo QUADRO 3, que no levantamento 
dessa produção, não incluímos esse aspecto positivo usado pela acadêmica. Outra observação que também nos levou a salientar tal resultado foi o fato de que, ao notarmos a marcação de um aspecto negativo em uma das produçóes iniciais, nos demos conta de que não havíamos marcado como positivo tal aspecto que havia sido contemplado pelas demais acadêmicas.

Entendemos que, em decorrência do processo analítico por nós vivenciado, um novo olhar diretamente nos dados permitiria uma compreensão mais aprofundada das produçôes das acadêmicas quanto à questão discutida. Porém, os dados já seriam outros que não os inicialmente levantados no decorrer da pesquisa.

Apesar de considerarmos válida a possibilidade de que a interpretação sobre a saliente marcação dos aspectos negativos nos levantamentos das produçóes das acadêmicas ter sido decorrente de uma atitude de enxergar mais o aspecto negativo do que o positivo nas produções dos alunos, ocorreu-nos, posteriormente, uma segunda possibilidade interpretativa. $\mathrm{O}$ fato de tais levantamentos terem se constituído de itens majoritariamente negativos pode ter como razão o instrumento para a avaliação dessas produções, no caso, o modelo didático do gênero em questão, o qual limitava o olhar dentro de seus parâmetros, considerando-se ainda a natureza do $\mathrm{CV}$ como um gênero ser mais padronizado ou estável. Assim, ao usar o referido modelo didático como parâmetro da avaliação diagnóstica, o levantamento das primeiras produções das acadêmicas mostra que, embora elas pudessem reconhecer um currículo, o diagnóstico, limitando-se ao modelo, naquele momento inicial, mostrou mais destacadamente as lacunas e/ou as incorreções que a produção de um implicava. Apesar de tal possibilidade interpretativa, não haveria, entretanto, impedimento para que se procurasse levantar mais aspectos positivos do que foi levantado, conforme já discutido.

Outra lacuna evidenciada na análise dos dados, que se tornou bem evidente, até mesmo visível, nos quadros de organização dos dados, refere-se à capacidade de ação. Como podemos observar nos exemplos já citados, tal capacidade foi a menos marcada no levantamento dos aspectos da produção escrita das acadêmicas, realizado pelas professoras-pesquisadoras. Como na primeira produção, os espaços destinados à capacidade de ação nos quadros se mostram em grande parte vazios também na segunda produção, como é o caso das acadêmicas Gi, Lo, Me, Fran, Ry, Re.

A evidência de tal resultado por ocasião da organização dos dados nos respectivos quadros nos intrigou e nos levou de volta a examinar as ferramentas 
mediadoras ${ }^{6}$ utilizadas no desenvolvimento da sequência didática planejada. O material apostilado contemplava tal capacidade, o resgate das lembranças sobre o desenvolvimento da sequência também mostrava que ela tinha recebido a devida atenção e o enunciado ${ }^{7}$ que orientava a segunda produção também havia alertado para que ela fosse considerada ("Consider the elements of the context of production”). Na lista de controle, porém, não constava tal orientação. Apesar de alertado no referido enunciado, também não se pedia nele que as acadêmicas explicitassem, à parte, os elementos do contexto de produção que caracterizam tal capacidade, já que se tratava, no final das contas, de uma tarefa escolar, e a produção não teria, naquele momento, circulação real na devida esfera de ação social. Assim, os aspectos categorizados como pertencentes a tal capacidade em algumas produções das acadêmicas se sustentam em possíveis inferências de que as acadêmicas podem ter conscientemente considerado alguns aspectos da situação de produção e isso tenha sido marcado nas escolhas que fizeram para elaborar a segunda produção. Um exemplo seria a escolha de apresentar primeiro as referências profissionais se o $\mathrm{CV}$ fosse enviado para solicitar emprego, ou primeiro as referências acadêmicas se se tivesse pensado em enviá-lo para solicitar uma bolsa de estudos, como eram as opções da atividade desenvolvida.

Diante de tais resultados, voltamo-nos, então, para as possíveis razões da lacuna no que se refere à capacidade de ação. Apesar de não ter sido uma ação consciente, entendemos que a não marcação da capacidade de ação na lista de controle pelas formadoras-pesquisadoras, por exemplo, se deve, talvez, ao fato de o gênero trabalhado ser um gênero mais estável ou padronizado. Assim, se as alunas não considerassem conscientemente as informações do contexto de produção, não haveria grandes problemas na composição dos seus enunciados ou nos efeitos de sentido desejáveis de serem atingidos em seus interlocutores.

${ }^{6}$ Uso voluntário de dicionários, as próprias colegas, a lista de controle, os exercícios da sequência didática. Vale ressaltar que tal sequência foi apresentada em artigo de Calvo e Borghi (2009), nos anais do V SIGET.

7 Enunciado para a segunda produção:

"Choose one of the ads above and write your CV applying for the jobs or the scholarship offered.

- First of all, based on your choice, think about the appropriate information and order you'll focus on your text. · Consider the elements of the context of production;

- Decide on the specific language: - Appropriate / action verbs; - Verb tenses; - Specialized terms and vocabulary". 
Além dessa possível leitura do dado, aventamos a hipótese de que uma longa prática pedagógica que não considerava as capacidades de linguagem, em especial a de ação, prática essa tanto a que fomos submetidas como aprendizes de línguas, quanto a nossa própria prática como professoras de línguas, pode nos ter levado a não salientar a necessidade de considerar e de marcar explicitamente os aspectos da situação de produção que afetam diretamente as decisões discursivas e linguístico-discursivas para a produção de um gênero do discurso. Tal leitura nos alertou para um cuidado maior na orientação de futuros trabalhos com gêneros no que diz respeito à importância da capacidade de ação em relação às outras capacidades de linguagem. Ações mais eficientes a serem pensadas para a elaboração do planejamento e para o desenvolvimento de sequências didáticas, no que diz respeito a tal questão, já foram, portanto, incluídas em nossa agenda de ensino e de pesquisa.

Como uma última questão a ser salientada nesta discussão dos resultados, apontamos para o fato de que, diferentemente da lacuna referente à capacidade de ação recém discutida, os dados também revelam que houve um número maior de itens marcados no que diz respeito às capacidades discursiva e linguístico-discursiva. Como os quadros apresentados anteriormente já contêm exemplos do levantamento das capacidades discursiva e linguísticodiscursiva da primeira produção, oferecemos, agora, exemplos da segunda produção de duas acadêmicas, ${ }^{8}$ Lo e Me. Vale ressaltar a positividade dos dados, tomando como comparação a negatividade da primeira produção.

Uma possível razão que vislumbramos para a maior marcação dos aspectos discursivos e linguístico-discursivos recai no fato de que eles ainda parecem ser mais enfatizados no desenvolvimento das atividades da sequência didática. A ênfase em tais aspectos parece ocorrer independentemente de se estabelecerem ou não relações entre eles e os aspectos da situação de produção (capacidade de ação).

${ }^{8}$ Consultar também os dados referentes à segunda produção de Gi no QUADRO 1. 
QUADRO 4

Levantamento dos aspectos característicos do gênero CV da segunda produção de Lo

\begin{tabular}{|c|c|c|}
\hline Produçōes & $\begin{array}{l}\text { Capacidades } \\
\text { de linguagem }\end{array}$ & Lista de controle \\
\hline \multirow{2}{*}{$\begin{array}{c}2^{\mathbf{a}} \\
\text { produção }\end{array}$} & Capacidade discursiva & $\begin{array}{l}\text { (+) use of chronological order maintained } \\
\text { and improved; } \\
(+) \text { subtitles / heading continue to be emphasized; } \\
(+) \text { good spaces between the topics. }\end{array}$ \\
\hline & $\begin{array}{c}\text { Capacidade } \\
\text { linguístico-discursiva }\end{array}$ & $\begin{array}{l}\text { (+) right use of specific terms; } \\
(+) \text { use of action verbs in the past maintained } \\
\text { and improved; } \\
\text { (+) correct use of the verb tense (past); } \\
\text { (+) right way to write the address. }\end{array}$ \\
\hline
\end{tabular}

QUADRO 5

Levantamento dos aspectos característicos do gênero $\mathrm{CV}$ da segunda produção de $\mathrm{Me}$

\begin{tabular}{c|c|l}
\hline Produções & $\begin{array}{c}\text { Capacidades } \\
\text { de linguagem }\end{array}$ & \multicolumn{1}{c}{ Lista de controle } \\
\hline \multirow{2}{*}{$2^{\mathbf{a}}$} & Capacidade discursiva & $\begin{array}{l}(+) \text { use of dates; } \\
(+) \text { use of reverse chronological order; } \\
(+) \text { emphasis on headings maintained. }\end{array}$ \\
\cline { 2 - 3 } produção & $\begin{array}{c}\text { Capacidade } \\
\text { linguístico-discursiva }\end{array}$ & $\begin{array}{l}(+) \text { use of appropriate terms /words; } \\
(+) \text { use of action verbs; } \\
(+/-) \text { correct use of specific terms and wrong } \\
\text { choice of new specific words. }\end{array}$ \\
\hline
\end{tabular}

Considerando as discussōes desenvolvidas na presente seção, entendemos que elas procuram responder ou dialogar com as perguntas levantadas anteriormente, quais sejam: como se pode observar o desenvolvimento das acadêmicas no que tange às diferentes capacidades de linguagem, tomando por base sua produção inicial e sua segunda produção de um CV em inglês?; o que os dados (quadros) podem sugerir dos procedimentos pedagógicos e analíticos das formadoras-pesquisadoras?

Assim, mesmo com as lacunas no que diz respeito à capacidade de ação, ao fato de, no levantamento da primeira produção escrita do CV, se priorizarem seus aspectos negativos, deixando de salientar mais aspectos 
positivos do que foi feito, à possível ênfase maior nas capacidades discursiva e linguístico-discursiva, podemos observar que, de um modo geral, o trabalho desenvolvido com o referido gênero por meio da sequência didática elaborada para tal fim resultou positivo. Na verdade, notou-se um aprimoramento na capacidade das acadêmicas no que tange à produção de $\mathrm{CVs}$, aprimoramento esse, a nosso ver, proporcionado provavelmente pelo seu contato com as diferentes ferramentas de mediação disponibilizadas no desenvolvimento da atividade em suas várias etapas, conforme já apontado.

\section{Considerações finais}

Diante do que se apresenta na seção anterior, em relação ao ensino de gêneros com acadêmicas de Letras-inglês, os resultados discutidos apontam para medidas possíveis de serem tomadas no sentido de fortalecer e / ou suprir procedimentos que se mostraram importantes para serem pensados em trabalhos futuros. Um exemplo disso seria um trabalho mais explicitado com a capacidade de ação, como indicado antes.

Entendemos, portanto, que os resultados e a respectiva discussão apresentados neste artigo ilustram como um trabalho com gêneros textuais por meio de sequências didáticas em contexto de formação docente inicial pode auxiliar o processo de ensino-aprendizagem de língua estrangeira, no caso a inglesa, uma vez que permite aos acadêmicos se aproximarem mais da realidade e perceberem a utilidade social de uma aprendizagem dessa natureza. Aprendizagem essa que os instrumentaliza para se comunicarem com seus interlocutores numa dada situação social ou profissional, conforme preconizam Tamarozi e Cristovão (2007).

Lançando mão de prerrogativa anterior ao usarmos dados de outros instrumentos de pesquisa, sem que fossem alvo central da discussão, apresentamos o depoimento de uma das acadêmicas participantes da pesquisa para corroborar tais consideraçóes.

A sequência didática "apresentada" permitiu conhecimento sobre a estrutura de um currículo. Foi uma experiência muito boa e bem aproveitada, pois sabemos que o currículo é inevitável na vida profissional e "aprender" fazer/estruturá-lo em sala torna-se mais fácil. É interessante unir "utilidades" ao ensino (pois fica claro o que você está fazendo e para que está fazendo). (A1). 
Para enriquecer e complementar os resultados da presente análise e, assim, melhor avaliar o uso de uma sequência didática do gênero $\mathrm{CV}$ no ensino de inglês na formação docente inicial, é nosso propósito nos ocuparmos, em uma próxima oportunidade, da visão do sujeito-aprendiz desse processo triplo de ensino-aprendizagem-pesquisa, além da visão do formador-pesquisador que ora procuramos apresentar, tomando, então, outros dados também coletados como centrais.

Em que pese o auxílio positivo do uso do gênero CV para o ensinoaprendizagem de inglês no contexto investigado, vale salientar que, ao abordarmos, de certa forma, a visão do formador-pesquisador, foi-nos possível observar como o bom ou o mau uso das potencialidades e dos limites de ferramentas pedagógicas para o ensino-aprendizagem dos gêneros do discurso no ensino superior sugere ou requer uma formação adequada dos formadores, os quais não dispõem de experiências vividas na esfera escolar que lhe sirva de base para esse tipo de trabalho. Deixamos, portanto, essa questão em aberto para que seja alvo possível de investigaçóes futuras.

\section{Referências}

BAKHTIN, M. Os gêneros do discurso. In: BAKHTIN, M. Estética da criação verbal. 4. ed. Trad. Paulo Bezerra. São Paulo: Martins Fontes, 2003. p. 261-306. BONINI, A. Ensino de gêneros textuais: a questão das escolhas teóricas e metodológicas. Trabalhos em Lingüistica Aplicada, v. 37, n. 37, p. 7-23, jan/jun, 2001.

BRAIT, B.; MELO, R. de. Enunciado / enunciado concreto /enunciação. In: BRAIT, B. (Org.). Bakhtin: conceitos-chave. São Paulo: Contexto, 2005.

BRASIL. Secretaria de Educação Fundamental. Parâmetros Curriculares Nacionais: terceiro e quarto ciclos do ensino fundamental; língua estrangeira. Brasília: MEC/SEF, 1998.

BRASIL. Orientaçôes Curriculares para Ensino Médio. Linguagens, Códigos e suas Tecnologias / Secretaria da Educação Básica. - Brasília: Ministério da Educação, Secretaria da Educação Básica, 2006. Disponível em: <http://portal.mec.gov.br/ seb/arquivos/pdf/book_volume_01_internet.pdf >. Acesso em: 24 nov. 2009. CALVO, L. C. S.; BORGHI, C. I. B. Gêneros discursivos e sequências didáticas na formação docente inicial de língua estrangeira. In: SIGET - SIMPÓSIO INTERNACIONAL DE GÊNEROS TEXTUAIS, 5, 2009, Caxias do Sul. Anais... Caxias do Sul: Rio Grande do Sul. Universidade de Caxias do Sul, 2009, p. 1-20. CD-ROM. 
CRISTOVÃO, V. L. L. (Org.). Modelos didáticos de gênero: uma abordagem para o ensino de língua estrangeira. Londrina: UEL, 2007.

CRISTOVÃO, V. L. L. Gêneros Textuais, Material Didático e Formação de Professores. Signum: Estudos da Linguagem, Londrina, n. 8/1, p. 159-172, jun. 2005.

CRISTOVÃO, V. L. L.; TORRES, A. C. G. Gênero Textual como instrumento para o engajamento do aprendiz no processo de avaliação da produção escrita. In: MACHADO, L. T.; CRISTOVÃO, V. L. L.; FURTOSO, V. B. (Org.). Aspectos da linguagem: consideraçôes teórico-práticas. Londrina: UEL, 2006. p. 37-57. DIONISIO, A. P.; MACHADO, A. R.; BEZERRA, M. A. Gêneros Textuais \& Ensino. Rio de Janeiro: Editora Lucerna, 2005.

DOLZ, J.; NOVERRAZ, M.; SCHNEUWLY, B. Sequências didáticas para o oral e a escrita: apresentação de um procedimento. In: SCHNEUWLY, B.; DOLZ, J. Gêneros orais e escritos na escola. Trad. Roxane Rojo e Glaís Sales Cordeiro. São Paulo: Mercado de Letras, 2004. p. 95-128.

FIORIN, J. L. Introdução ao pensamento de Bakhtin. São Paulo: Ática, 2006.

GONÇALVES, A. V. Gêneros textuais e reescrita: uma proposta de intervenção interativa. 2007. Tese (Doutorado) - Programa da Faculdade de Ciências e Letras - UNESP, Araraquara em Linguística e Língua Portuguesa, 2007.

KARWOSKI, A. M.; GAYDECZKA, B.; BRITO, K. S. (Org.). Gêneros textuais: reflexōes e ensino. Rio de Janeiro: Editora Lucerna, 2006.

MEURER, J. L. O Conhecimento de Gêneros Textuais e a Formação do Profissional da Linguagem. In: FORTKAMP, M. B. M.; TOMITCH, L. M. B. (Org.). Aspectos da Lingüística Aplicada. Florianópolis: Editora Insular, 2000.

PARANÁ. Diretrizes Curriculares da Educação Básica Língua Estrangeira Moderna. Secretaria de Estado da Educação Básica do Paraná, Departamento de Educação Básica. Paraná, 2008.

PASQUIER, A.; DOLZ, J. Um decálogo para ensinar a escrever. Cultura y Educación, n. 2, p. 31-41, Trad. Roxane Rojo. Madrid: Infancia y Aprendizaje, 1996.

SCHNEUWLY, B.; DOLZ, J. Gêneros orais e escritos na escola. Trad. Roxane Rojo e Glaís Sales Cordeiro. São Paulo: Mercado de Letras, 2004.

TAMAROZI, L.; CRISTOVÃO, V. L. L. O contexto escolar: alvo da transposição didática do projeto Modelos Didáticos de Gêneros. In: CRISTOVÃO, V. L. L. (Org.). Modelos didáticos de gênero: uma abordagem para o ensino de língua estrangeira. Londrina: UEL, 2007. 


\section{APÊNDICES}

\section{A - Resumo do modelo didático do gênero CV}

\section{1 - Parâmetros da Situação}

- Finalidade

Porque trabalhar este gênero no curso de Letras: - necessidade de alunos conhecerem como fazer um Curriculum vitae; - exigência para candidatos a concursos; exigência para obtenção de emprego; - conhecer o gênero textual "Curriculum vitae", as principais características que o compóem e o meio social em que circula.

- Público-alvo - Acadêmicos do Curso de Letras - $4^{\circ}$ ano da habilitação Português/ Inglês.

- Conteúdo - Dados pessoais, qualificação e dados profissionais.

2- Opções do Gênero - O lugar social onde circula o gênero Curriculum vitae.

O gênero Curriculum vitae circula nas esferas de trabalho e na esfera acadêmica. Em pequenas empresas, o curriculum vitae é endereçado ao diretor. Em empresas de porte médio, o curriculum pode ser enviado ao chefe de departamento e em grandes empresas, haverá sempre um Departamento de Recursos Humanos, para onde deve ser encaminhado o curriculum. Em escolas, o mesmo deve ser enviado ao diretor ou coordenador pedagógico.

\section{3- Conteúdo}

O Curriculum vitae (CV) deve conter: dados pessoais, formação acadêmica, experiência profissional, habilidades e referências. $\mathrm{Na}$ realidade brasileira, os principais tópicos são: dados pessoais, formação acadêmica, experiência profissional, cursos e outras informações. 


\section{4- Características principais}

- ordem cronológica reversa - as informações mais recentes são colocadas primeiro;

- impressão em qualidade boa, papel A4. Não anexar documentos extras, cartas ou certificados;

- apresentação do currículo de maneira organizada e clara;

- deve ser de fácil leitura, curto e atraente;

- ser específico, claro, direto. Evitar o uso de sentenças completas;

- usar verbos de ação: realizou, colaborou, encorajou, estabeleceu, fundou, gerenciou, ministrou, dirigiu etc, no tempo verbal do passado, exceto para as atividades atuais.;

- não usar o pronome pessoal "eu";

- utilizar espaços entre os tópicos;

- os títulos devem ser enfatizados com o uso de letras maiúsculas ou negrito;

- não usar abreviações;

- verificar cuidadosamente a gramática e a grafia;

- em alguns países há uma descrição das atividades realizadas nos empregos anteriores e no atual;

- linguagem específica: GPA, Dean's Test. 


\section{$B$ - Lista de controle do gênero CV}

\section{CONTROL LIST - CURRICULUM VITAE}

- subtitles / headings must be emphasized;

- use of spaces between the topics;

- use of specific words / terms;

- verbs in the past or present tense;

- use of action verbs;

- no use of complete sentences;

- no use of the personal pronoun "I";

- reverse chronological order of the information.

Recebido em dezembro de 2009. Aprovado em janeiro de 2010. 